\title{
Reduction of avian diversity in created versus natural and restored wetlands
}

Esther Sebastián-González ${ }^{1,2}$ and Andy J. Green ${ }^{3}$

${ }^{1}$ Departamento de Ecologia. Universidade de São Paulo, São Paulo, Brazil

${ }^{2}$ Department of Biology. University of Hawai’i, 200 W Kawili st. Hilo, HI 96720, USA

${ }^{3}$ Department of Wetland Ecology, Estación Biológica de Doñana EBD-CSIC, Sevilla, Spain

Corresponding author: Esther Sebastián-González, Department of Biology. University of Hawai’i, 200

W Kawili st. Hilo, HI 96720, USA. E-mail: esebgo@gmail.com. Telephone +1 8084641122

Decision date: $18-\mathrm{Dec}-2015$

This article has been accepted for publication and undergone full peer review but has not been through the copyediting, typesetting, pagination and proofreading process, which may lead to differences between this version and the Version of Record. Please cite this article as doi: [10.1111/ecog.01736]. 


\section{Abstract}

Natural wetland ecosystems continue to suffer widespread destruction and degradation. Many recent studies argue that artificial or restored wetlands compensate for wetland loss and are valuable for waterbird conservation. However, detailed comparisons of the value of natural, artificial and restored wetlands are lacking. Our aim was to assess if the restoration or creation of wetlands can fully compensate for the loss of natural wetlands for waterbirds. We compared the waterbird communities in a set of 20 natural, restored and artificial wetlands, all of which are considered important for waterbirds and are located within the same protected area (Doñana Natural Space, south-west Spain). We used different measures of diversity, including phylogenetic relatedness, and the proportion of threatened species at national, European and international levels. We found that artificial wetlands have consistently lower value than restored and natural wetlands, with little difference between the latter two. Natural wetlands are essential for conserving diversity across the tree of life and for threatened species, but restored wetlands can be of similar value and can assure maintenance of key ecological processes. Thus, when economic costs per unit area are similar, resources for wetland conservation are better invested in restoration projects than in wetland creation, and caution is required when suggesting that artificial wetlands compensate for the loss of natural wetlands.

Keywords: Habitat creation; phylogenetic relatedness; restoration; Simpson diversity; species richness; threatened species; waterbird 
Wetlands are considered one of the most productive ecosystems on Earth. They provide many ecosystem services such as protection from flooding and erosion, water purification, nutrient retention, carbon storage, biodiversity conservation and production of food or fuel (Chmura et al. 2003, Mitsch and Gosselink 2007). However, wetlands are also among the most threatened habitats in the world, have suffered extensive drainage, degradation and fragmentation (Dudgeon et al. 2006), and are highly susceptible to the effects of global climate change (Cížková et al. 2013).

To some extent, the ongoing loss of natural wetlands is compensated by the creation of vast areas of artificial wetlands. In some cases, these new wetlands were built specifically for conservation purposes. However, the great majority were created for human activities, particularly agriculture and aquaculture (Sebastián-González et al. 2010, Sripanomyom et al. 2011, Márquez-Ferrando et al. 2014). In the Mediterranean region, where c. $50 \%$ of natural wetland area was lost during the $20^{\text {th }}$ century, artificial wetlands represent approximately one quarter of the total surface of wetlands (Perennou et al. 2012). This proportion is even higher in countries such as Spain, where artificial wetlands now represent up to $75 \%$ of the total wetland area (Perennou et al. 2012). To a lesser extent, the loss of natural wetlands is also compensated for by the restoration of degraded wetlands, with the general aim of recovering physicochemical and biological processes that were lost during the degradation of natural wetlands (Williams and Faber 2001). However, wetland restoration can be expensive (Copeland 2010) and recent studies have questioned their capacity to recover original levels of ecosystem functions such as hydrology or nutrient cycling (Moreno-Mateos et al. 2012).

There is an urgent need to increase our understanding of the ecological value of created and restored wetlands in comparison with natural ones. One possible approach is to compare the animal populations that use them. Amongst wetland fauna, waterbirds have received special attention owing to the cultural and provisioning services they provide (Green and Elmberg 2014). They are used as flagships for wetland conservation and as bioindicators of ecological change. They are relatively easy to monitor and, for many major wetlands, waterbird counts represent the only ongoing form of environmental monitoring. Repeated studies have emphasized the importance of artificial wetlands for waterbirds (e.g. Sripanomyom et al. 2011, Marquez-Ferrando et al. 2014, Navedo et al. 2014). Much less attention has been paid to the value of restored wetlands for waterbirds (e.g. Sebastián-González and Green 2013). There is a shortage of systematic studies that compare the diversity of birds using artificial, restored and natural wetlands, while controlling for the influence of confounding factors such as surface area. There is a need for a

'This article is protected by copyright. All rights reserved.' 
standardized comparison between restored, artificial and natural wetlands that allows assessment of their value for waterbird and biodiversity conservation. However, few areas hold all three wetland types so as to make a meaningful comparison between them possible.

Many studies have focused on species richness to identify priority areas for conservation because it is a measure easy to quantify and interpret (Cadotte and Davies 2010). Nevertheless, this ignores the differences among communities in terms of relative abundance of particular species, presence of threatened species and their functional or evolutionary characteristics. Species that are closely related are more likely to share common features such as ecological niches or functional traits (Faith 1992). Thus, a high phylogenetic diversity might reflect not only community functional diversity but also its ability to adapt to future conditions (Vane-Wright et al. 1991, Cadotte and Davies 2010). Conservation biologists should thus incorporate different measures of community diversity and uniqueness when comparing habitat types and management options. Converting forests into agricultural systems leads to a major loss of avian phylogenetic diversity (Frishkoff et al. 2014), and similar studies in aquatic systems are required.

In this study, we compare the waterbird community among a set of natural, restored and artificial wetlands in an iconic wetland complex in Southern Spain, the Donana Natural Space. This area is one of the most important in Europe and the Mediterranean region for waterbirds, and contains a range of sites created or restored with the aim of benefitting birds (Rendón et al. 2008, Ramo et al. 2013). We analyze how the bird communities that use restored and artificial wetlands differ from those in natural wetlands, while controlling for the general and well-documented trend that larger wetlands attract more birds (Guareschi et al. 2015). We use a combination of different metrics related to the richness, abundance, level of extinction threat and phylogenetic uniqueness of the communities to enable a thorough comparison. The rapid expansion of artificial wetlands and the widespread belief expressed in the literature that they can substitute natural wetlands render our study of broad significance. We discuss the implications of our results for the recovery of major ecological processes in wetlands.

\section{Methods}

\section{Study area}

Doñana Natural Space $(108,429$ ha) is located in the Guadalquivir estuary in South-western Spain (Fig.

1). Doñana is catalogued as a Ramsar site, a European Union Special Protected Area and a UNESCO

World Heritage Site (www.ramsar.org; www.unesco.org) because of its importance for many animal and 
plant species, especially waterbirds (Rendón et al. 2008, Ramo et al. 2013). It has a Mediterranean climate with Atlantic influence and dry, hot summers and short, mild winters. Rainfall is highly variable between years (ranging from 173 to $784 \mathrm{~mm}$, for the period 2002 to 2012) and occurs principally between October and March. Doñana contains a complex mosaic of natural, artificial and restored wetlands within what was originally the alluvial flood plain of the Guadalquivir River. We selected 5 restored, 5 natural and 10 artificial wetlands (see Table A1 in Appendix 1, Supplementary material for details) interspersed across different parts of Doñana Natural Space (Fig. 1). These sites were selected because they are considered important for waterbirds and are monitored regularly for that reason.

During the $20^{\text {th }}$ century, large areas of the original marsh were drained and transformed into agricultural areas, rice fields, salt pans or fish farms. The natural and restored study wetlands are mainly temporary natural marshes, which are fed by surface flow and direct rainfall, with some lagoons in the dunes which are largely aquifer-fed (García and Marín 2006). They are mainly flooded with heavy rains in fall and winter, and they typically dry out completely between July and October. Restoration occurred during a joint ecotourism-aquaculture project in Veta la Palma in the early 1990s (two sites), and an ambitious project ("Doñana 2005”, García and Marín 2006) to recover some of the original hydrology of the extensive marsh system in the early 2000s (three sites). Seven and two of the artificial sites, respectively, were created during the same projects, the tenth being created to provide an attraction at a visitor centre for Doñana National Park (Santoro et al. 2010). The artificial wetlands were located in areas that had once been temporary marsh, but had an entirely artificial hydrology, and were created by the construction of dykes to allow the water level to be raised above surrounding land. Restored wetlands had a natural or semi-natural hydrology in which water levels are not artificially raised by dykes.

The inundated surface area was variable for our study wetlands, so we used estimates computed from satellite images (Landsat MSS, TM and ETM+) in the months that corresponded to the waterbird surveys, provided by the Laboratorio de Sistemas de Información Geográfica y Teledetección (LAST) of the EBD-CSIC (Bustamante et al. 2009, http://venus.ebd.csic.es/imgs/). For each month and wetland we calculated the total area covered by water, and we used this variable in our models, instead of the total area of the wetland basin (which was often partially dry).

\section{Waterbird surveys}

'This article is protected by copyright. All rights reserved.' 
All the wetlands were surveyed monthly between 2003-2013 by experienced observers as part of a monitoring program carried out by the Doñana Biological Station (EBD-CSIC, http:// wwwrbd.ebd.csic.es/Seguimiento/seguimiento.htm). Some scheduled counts were missing because of bad weather conditions or logistical problems. All aquatic birds present were identified to species and counted. We excluded raptors, corvids and other non-aquatic species from analyses. Every wetland was visited on foot in a single day and surveyed from one or more positions along the shoreline with binoculars ( 8 x 50) and a telescope $(20 \times 60)$. Birds flying overhead were excluded. We analysed data from the breeding (from April to June) and wintering (from December to February) months. We summed the waterbirds found in the three surveys performed within the same season and the same year into one datum.

\section{Diversity measures}

We calculated five different measures of diversity to describe the waterbird community at each of the wetlands. We first calculated the total abundance (number of individuals per wetland) and richness (i.e. number of species per wetland) for each season and year. We then calculated the Simpson Diversity Index (D) as:

$$
D=1-\sum_{i=1}^{S} p_{i}^{2}
$$

Where $p_{i}$ is the proportional abundance of species $i$. The value of this index ranges between 0 and 1 , with higher values indicating greater diversity. The index represents the probability that two individuals randomly selected from a sample belong to different species.

Since the body mass of the species recorded varies by more than two orders of magnitude, we also calculated a Simpson Biomass Index where we weighted the abundance by the body mass of each species (Dunning 2007) to give more importance to larger species. We used the same formula as for D, but in this case $p_{i}$ is the proportional biomass of species $i$. Then, we calculated two measures of phylogenetic diversity (Webb et al. 2002). The Mean Pairwise Distance (MPD) calculates the mean of the pairwise distances of all the species in the community, while the Mean Pairwise Weighted Distance (MPWD) uses the same approach but weights the distances by species abundance. These two measures are based on a distance matrix calculated for each pair of species using the resolved phylogeny in Jetz et al. (2012). See Fig. A3, Appendix 1, in supplementary material for the complete phylogeny we used. We calculated 
MPD and MPWD for 100 equiprobable trees and we calculated the average value for each community. All the analyses were performed using the Ape and Picante packages (Paradis et al. 2004, Kembel et al. 2010) in R 2.15.1 (R Development Core Team 2012).

Finally, we assessed the relative proportion of threatened species in each wetland (i.e. number of threatened species divided by the total number of species detected in that survey) using four different classifications (see Table A4, Appendix 1 for the complete list of species and their threatened status). We used the IUCN list of globally threatened species (IUCN 2014), the Red Data Book of the Birds of Spain (Madroño et al. 2004) and the European Red List of Birds (BirdLife International 2015). For the European Red List of Birds, we used the list for the 27 countries that were Member States of the European Union during the period covered by the 2008-2012 round of reporting under Article 12 of the Birds Directive (Directive 2009/147/EC). For these indexes, we considered a species to be threatened if it was catalogued as "Near threatened", "Vulnerable", "Endangered" or "Critically Endangered". We also included an index to measure the proportion of species included in the Annex 1 of the European Birds Directive, which denotes threatened species at the European level.

\section{Statistical analyses}

Generalized linear mixed models (GLMMs) were used to compare each of the diversity and threatened status indices between the three types of wetlands (restored, natural, and artificial). As we were interested in controlling for differences in abundance (since sites with more birds inevitably hold more species), we included total waterbird counts per site (i.e. abundance) as a covariate. Thus, the analyses test for differences in diversity and proportion of threatened species for similar values of abundance. As the waterbird populations present seasonal differences, we also included season (wintering vs. breeding) as a covariate in the model. Finally, we included the survey year as a random variable to control for possible temporal pseudoreplication. For each variable, we selected the variable transformation and error function that better fitted the data. We used the Poisson distribution for Richness, Binomial for the proportion of threatened species, Gamma for MPD, MPWD, and Simpson Biomass indexes, and Gaussian for the Simpson index. We used the glmer function from the lme4 package. For each diversity index, we constructed two models, one null model including only the covariates and the random variable and a second one including also a variable for the type of wetland (restored, natural, artificial). We compared

'This article is protected by copyright. All rights reserved.' 
the models using the Akaike Information Criterion, considering two models that differed in AIC by less that 2 to be equally probable.

Although we used the error distribution that fitted our data best, there were significant differences (Kolmogorov-Smirnov test, $\mathrm{P}<0.05$ ) among the theoretical distribution and our data for four out of the nine variables calculated (Simpson diversity, Simpson Biomass, MPD and MPWD). Thus, we verified that our results were robust by using a randomization approach. To do so, we re-calculated the GLMM model including the abundance and season as covariates, the year as random variable and the wetland type as explanatory variables, but randomizing the diversity and threatened status metrics. We repeated this analysis 1000 times to identify the range of values that the coefficient of the variable "type" (or any other variable of interest) can take for a random relationship between the dependent variable and "type". Then, we checked whether the coefficients of the variable "type" in our model were within the range of values of the coefficients of the models with the randomized variables.

To further investigate the robustness of our results, we also wanted to compare the diversity between different wetland types while removing the effect of repeatedly measuring the same wetland over time. We therefore repeated the GLMMs with abundance and season as covariates, year as a random variable and wetland identity (i.e. a code that identifies each of the 20 sampled wetlands) as an explanatory factor. Then, we calculated the predicted diversity (or proportion of threatened species) for each of the 20 individual wetlands according to the model estimates of this GLMM and performed ANOVAs to compare these predicted values between the three-wetland types (artificial, restored or natural). Post-hoc tests were performed using the Tukey HSD test. The analyses were performed in R using the lme4 package (Bates et al. 2009).

Finally, because the distribution of natural, restored and artificial wetlands within the protected area is not random, we tested if the diversity and threatened status parameters were related to the geographic location of the wetlands (i.e. if wetlands located in some areas of the park had higher bird diversities than others). We used Moran's I test in the ape library of R (Paradis et al. 2004) to do the analyses based on geographical coordinates.

\section{Results}

Our dataset comprised between 51 and 66 surveys (depending on the availability) for each of the 20 wetlands. A total of 4,269,129 waterbirds from 80 different species were counted. The mean surface area 
for natural wetlands was slightly lower than that of artificial wetlands, and the mean area for restored wetlands was the highest (Table 1). The average bird abundance and richness per survey was highest in the restored wetlands, but this was related to their greater surface area (Table 1). Artificial wetlands showed the lowest values for all these parameters, and also for all the diversity indexes measured (whether phylogenetic or not). Natural wetlands had higher diversity indices than restored wetlands in four of six cases (Table 1). None of the studied variables presented spatial autocorrelation (all $\mathrm{P}>0.25$ ), indicating that the variation between wetland types is not due to differences in geographic location.

The percentage of threatened species was consistently higher in restored and natural wetlands than in artificial ones, especially for the IUCN and European threatened lists (Table 1). Some threatened species were never found in the artificial wetlands, such as the Ferruginous duck Aythya nyroca and the Marsh sandpiper Tringa stagnatilis. Other threatened species had much higher abundances in the natural or restored wetlands than in the artificial, such as the Black-tailed godwit Limosa limosa, the Redknobbed coot Fulica cristata, or the Common snipe Gallinago gallinago (Table A4 in Appendix 1).

When we analyzed the significance of wetland type (natural-restored-artificial), we included abundance as a covariate to assess how diversity metrics vary while accounting for the differential abundance (i.e. which type of wetland presents a higher diversity for a given abundance). The inclusion of the wetland type variable in the models always significantly improved the model fit, except for mean phylogenetic diversity and the proportion of threatened species according to Annex 1 of the Birds Directive (Table 2). For all the metrics, the results were similar when using randomizations, with at least one of the coefficients being different from randomized ones, indicating that wetland type is a significant variable (Supplementary material, Appendix 1, Table A5). The mean predicted diversity metric was always lowest for artificial wetlands and highest for natural wetlands (Fig. 2). Artificial wetlands showed significantly lower proportions of threatened species from the IUCN, European and Spanish lists (Table 3, Fig. 3).

When comparing the predicted diversity and proportion of threatened species at the level of individual wetlands, Richness, Simpson diversity (both with abundance and biomass data), proportion of threatened species and both phylogenetic metrics were significantly higher in restored and natural than in artificial wetlands. Species richness was also significantly higher in restored than in natural wetlands

(Table 3).

'This article is protected by copyright. All rights reserved.' 


\section{Discussion}

For a broad range of diversity metrics and proportion of threatened species, artificial wetlands consistently supported low diversities of waterbirds compared to restored and natural wetlands.

Compensating the loss of natural wetlands with artificial wetlands leads to a lower avian phylogenetic diversity, as does the conversion of forests into agricultural lands (Frishkoff et al. 2014). Our findings show the need for caution in interpreting many recent studies that emphasize the value of artificial wetlands for birds, which are based on limited analyses that underline the presence of important numbers of individual species (Sripanomyom et al. 2011, Marquez-Ferrando et al. 2014, Navedo et al. 2014). Some studies have reported that artificial wetlands were preferred as feeding habitat to natural wetlands (Masero 2003) or that foraging performance was similar between artificial and semi-natural wetlands (Elphick 2000). However, these studies have typically compared a single natural wetland with a very different type of artificial wetland (e.g. a deep lake with rice fields). Our study is unique in comparing waterbird communities simultaneously at different natural, restored and artificial wetlands within a single shallow, deltaic complex.

Higher diversity (as found here for waterbirds in natural and restored wetlands) has already been related to an increase in ecosystem function (Callaway et al. 2003, Cardinale et al. 2011) and in the ecosystem services provided by wetlands (Rey Benayas et al. 2009, Meli et al. 2014). Indeed, some ecosystem services cannot be recovered if diversity is not recovered first (Moreno-Mateos et al. 2012), and waterbirds play key roles in a variety of ecological processes (Green and Elmberg 2014). Higher number of species, especially if they are not highly phylogenetically related, may represent a wider spectrum of functions and roles in the community. For example, phylogenetic diversity is related to the roles of different species as vectors of dispersal for plants, invertebrates and microbes. This is due to variation between bird species both in which taxa they disperse (related to foraging behaviour), and where to (related to differing migratory behaviour, Green and Elmberg 2014). Low avian diversity in artificial wetlands may indicate a simplification of the food web (i.e. reduction in the number of trophic levels and/or reduced diversity at each level), and thus loss of some of the processes found in natural and restored wetlands. A community with high phylogenetic diversity also has a high evolutionary potential, which may increase the long-term resilience and stability of the community (Wilmers et al. 2002, Tilman et al. 2006, Lankau et al. 2011).

'This article is protected by copyright. All rights reserved.' 
Artificial wetlands also presented a lower proportion of threatened species than natural and restored wetlands. As the species richness in artificial wetlands is also lower compared to natural and restored wetlands, the differences in the total number of threatened species among wetland types may be even larger. Thus, as also shown in previous studies comparing artificial and natural wetlands (e.g. Li et al. 2013), artificial wetlands are not only less diverse, but also less likely to hold threatened species. The only index that did not show differences among wetland types was the proportion of species included in the Annex 1 of the EU Birds Directive. This index includes species that are abundant and increasing in the study area, such as the Black-winged stilt Himantopus himantopus or the Little egret Egretta garzetta, both of which are known to benefit from artificial wetlands in Doñana (Rendón et al. 2008, Ramo et al. 2013).

Other important wetland values such as carbon storage or soil properties have also been found to be lower in created wetlands than in natural ones (Ballantine and Schneider 2009, Bantilan-Smith et al. 2009). However, restored wetlands attempt to recover physico-chemical and biological processes present in the original natural wetlands, and have been shown to have reduced eutrophication and high food production (Brown 1999). Previous studies in Doñana suggest that the invertebrate communities are less diverse in artificial wetlands (Frisch et al. 2006, Kloskowski et al. 2009). Vegetation cover also presented some variation in the area, but the differences were not strictly related to the type of wetland. For example, the artificial Veta la Palma ponds have relatively little emergent vegetation (Kloskowski et al. 2009), whereas the artificial FAO ponds provide dense emergent vegetation cover especially suitable for colonial waterbirds (Santoro et al. 2010). However, recovery patterns of ecosystem functioning within and among restored and artificial wetlands are not entirely consistent (Moreno-Mateos et al. 2012, Meli et al. 2014). Thus, a study on the ecosystem services provided by the three wetland types in a system such as ours would give valuable insight to the value of wetland restoration or creation (see Walton et al. 2015).

We did not study artificial wetlands that could be expected $a$ priori to be poor for waterbird diversity (e.g. reservoirs which are generally deep and unproductive, or ricefields which provide low structural diversity and are typically subject to high levels of disturbance). All the artificial wetlands we studied were created within a protected area within the shallow marsh system of the delta of the Guadalquivir river, with the expectation that they would provide suitable habitat for birds. Several of them were created exclusively as bird habitat (Supplementary material, Appendix 1, Table A1). Although many sites were semi-natural fish ponds, these are large, shallow ponds which were created on top of a

'This article is protected by copyright. All rights reserved.' 
former marsh, partly to promote ecotourism through birds and to support the bird populations in Doñana (Walton et al. 2015). These artificial wetlands are unquestionably important for some waterbird species (Table A4, see also Rendón et al. 2008, Ramo et al. 2013) and are not subject to higher disturbance than the natural or restored ones. Indeed, the ability of different species to exploit artificial wetlands is a major determinant of their population trends in Doñana, with increasing species being those which make most use of artificial habitats (Rendon et al. 2008). However, our findings suggest that a switch from natural to artificial wetlands may imply an important loss of vertebrate diversity.

Having said that, any assessment of the value of wetland creation has to be context-dependent. New wetlands can be of considerable value for particular species of conservation or cultural interest (e.g. flamingoes in the case of Doñana, Rendón et al. 2008), or a major refuge for birds when natural wetlands are temporarily dry (e.g. Kloskowski et al. 2009). Artificial wetlands such as rice fields or irrigation ponds created for food production can provide added value for birds that may be critical for population viability (Sebastián-González et al. 2010, Navedo et al. 2014). Wetland creation may be the best alternative when restoration is not possible because former wetlands are now urbanized or highly degraded, or just because there were no previous wetlands in a region. Artificial wetlands might prove the better option if, for example, a larger area of habitat can be created than can be maintained via restoration or protection. In these cases, it is important to compare the potential benefits of the different options (creation, restoration or protection) to identify if the differences in the suitability of a type of wetland can compensate for the differences in their size. Given the highly limited budget available for conservation, cost-benefit analyses that identify which projects render the higher benefit with the lowest cost are a vital tool for waterbird conservation (Sebastián-González et al. 2011).

Our results underline the importance of using different diversity metrics to include information not only on species richness or diversity, but also on the proportion of threatened species or the phylogenetic relatedness of the species (see also Winter et al. 2013; Hidasi-Neto et al. 2013). Threatened bird species are often affected by habitat loss and may be particularly sensitive to changes in the ecosystem (Arponen 2012). As phylogenetically distinct species are likely to have distinct functional traits, the preservation of phylogenetic diversity implies functional diversity, which is highly important for the maintenance of ecological processes (Cadotte et al. 2011, Srivastava et al. 2012). The selection of conservation sites or target species may change depending on the criteria used (Hidasi-Neto et al. 2013), and a combination of

'This article is protected by copyright. All rights reserved.' 
different diversity metrics can improve selection of priority species and conservation areas (Trinidadefilho et al. 2012; Winter et al. 2013). Our study illustrates how this can work at a regional scale.

Since the creation of programs such as the "no net loss" in the 1980's in the United States, millions of dollars have been invested both in creation and restoration of wetlands for conservation purposes all over the world (Kusler and Kentula 1990). Our study underlines the importance of conserving remaining natural wetlands and the restoration of wetlands, compared to their replacement with artificial ones. Our main conclusions are that a) under similar economic costs per unit area, investment in wetland restoration rather than creation is likely to increase benefits for waterbird conservation; b) despite their value for some individual species, artificial wetlands may not provide an adequate systematic substitute for natural wetlands, and a switch from natural to artificial is likely to cause a critical loss in avian biodiversity.

Acknowledgements - The members of the Equipo de Seguimiento de Procesos Naturales de la Estación Biológica de Doñana conducted the counts and computerised the data. Inundated areas were calculated by the LAST-EBD remote sensing lab. Isabel Afán provided these data and prepared Figure 1. ES-G was supported by a FAPESP postdoctoral grant 2011/17968-2. Comments from C. Elphick and three anonymous reviewers greatly improved the quality of the manuscript.

'This article is protected by copyright. All rights reserved.' 


\section{REFERENCES}

Arponen, A. 2012. Prioritizing species for conservation planning. - Biodivers. Conserv. 21: 875-893.

Ballantine, K., Schneider, R. 2009. Fifty-five years of soil development in restored freshwater depressional wetlands. - Ecol. Appl. 19: 1467-1480.

Bantilan-Smith, M., Bruland, G.L., MacKenzie, R.A., Henry, A.R. and Ryder, C.R. 2009. A comparison of the vegetation and soils of natural, restored, and created coastal lowland wetlands in Hawaii. Wetlands 29: 1023-1035.

Bates, D., Maechler, M. and Dai, B. 2009. lme4: linear mixed effects models using S4 classes. R package version 0.999375-31.http://cran.r-project.org/web/packages/lme4

BirdLife International. 2015. European Red List of Birds. Office for Official Publications of the European Communities, Luxemburg.

Bunn, S.E. and Arthington, A.H. 2002. Basic principles and ecological consequences of altered flow regimes for aquatic biodiversity. - Environ. Manage. 30: 492-507.

Bustamante, J., Pacios, F., Diaz-Delgado, R. and Aragones, D. 2009. Predictive models of turbidity and water depth in the Doñana marshes using Landsat TM and ETM plus images. - J. Environ. Manage. 90: 2219-2225.

Cadotte, M.W. and Davies T.J. 2010. Rarest of the rare: advances in combining evolutionary distinctiveness and scarcity to inform conservation at biogeographical scales. - Divers. Distrib. 16: $376-385$.

Cadotte, M.W., Carscadden, K. and Mirotchnick, N. 2011. Beyond species: functional diversity and the maintenance of ecological processes and services. - J. Appl. Ecol. 48: 1079-1087.

Cardinale, B.J., Matulich, K.L., Hooper, D.U., Byrnes, J.E., Duffy, E., et al. 2011. The functional role of producer diversity in ecosystems. - Am. J. Bot. 98,: 572-592.

Callaway, J.C., Sullivan G. and Zedler, J.B. 2003. Species-rich plantings increase biomass and nitrogen accumulation in a wetland restoration experiment. - Ecol. Appl. 13: 1626-1639.

Chmura, G.L., Anisfeld, S.C., Cahoon, D.R. and Lynch, J.C. 2003. Global carbon sequestration in tidal, saline wetland soils. - Glob. Biogeochem. Cycles 17: 11.

Copeland, C. 2010. Wetlands: an overview of issues. Congressional Research Service, Washington D.C., USA, RL33483.

'This article is protected by copyright. All rights reserved.' 
Dudgeon, D., Arthington, A.H., Gessner, M.O., Kawabata, Z.I., Knowler, D.J., Leveque, C., et al. 2006. Freshwater biodiversity: importance, threats, status and conservation challenges. - Biol. Rev. 81: 163182.

Dunning, J.B. 2007. Handbook of Avian Body Masses. 2nd edition. CRC Press, Boca Raton, USA.

Elphick, C.S. 2000. Functional equivalency between rice fields and seminatural wetlands habitats. Cons. Biol. 14: 181- 191.

Faith, D.P. 1992. Conservation evaluation and phylogenetic diversity. - Biol. Conserv. 61: 1-10.

Frisch, D., Moreno-Ostos, E. and Green, A.J. 2006. Species richness and distribution of copepods and cladocerans in relation to hydroperiod and other environmental variables in Doñana, south-west Spain. - Hydrobiologia 556: 327-340.

García, F. and Marín, C. 2006. Doñana, water and biosphere. Spanish Ministry of Environment, Madrid. http://www.islandsonline.org/pdf/Donana\%20Water\%20and\%20Biosphere.pdf

Green, A.J. and Elmberg, J. 2014. Ecosystem services provided by waterbirds. - Biol. Rev. 89: 105-122.

Guareschi, S., Abellán, P., Laini, A., Green, A.J., Sánchez-Zapata, J.A., Velasco, J. and Millán, A. 2015.

Cross-taxon congruence in wetlands: assessing the value of waterbirds as surrogates of macroinvertebrate biodiversity in Mediterranean Ramsar sites. - Ecol. Ind. 49: 204-215.

Hidasi-Neto, J., Loyola, R.D. and Cianciaruso, M.V. 2013. Conservation Actions Based on Red Lists Do Not Capture the Functional and Phylogenetic Diversity of Birds in Brazil. - PLoS ONE 89: e73431.

IUCN 2014. The IUCN Red List of Threatened Species. Version 2013.2. <http://www.iucnredlist.org>. Downloaded on 21 January 2014.

Jetz, W., Thomas, G.H., Joy, J.B., Hartmann, K. and Mooers, A.O. 2012. The global diversity of birds in space and time. - Nature 491: 444-448.

Kembel, S.W., Cowan, P.D., Helmus, M.R., Cornwell, W.K., Morlon, H., Ackerly, D.D., et al. 2010. Picante: R tools for integrating phylogenies and ecology. - Bioinformatics, 26, 1463-1464.

Kloskowski, J., Green, A. J., Polak, M., Bustamante, J. and Krogulec, J. 2009. Complementary use of natural and artificial wetlands by waterbirds wintering in Doñana, south-west Spain. - Aquatic Conserv: Mar. Freshw. Ecosyst. 19: 815-826.

Kusler, J.A. and Kentula, M. E. 1990. Wetland creation and restoration: the status of the science. Island Press, Washington D.C., USA.

'This article is protected by copyright. All rights reserved.' 
Lankau, R., Jørgensen, P.S., Harris, D.J. and Sih, A. 2011. Incorporating evolutionary principles into environmental management and policy. - Evol. Appl. 4: 315-325.

Li, D., Chen, S., Lloyd, H., Zhu, S., Shan, K. and Zhang, Z. 2013. The importance of artificial habitats to migratory waterbirds within a natural/artificial wetland mosaic, Yellow River Delta, China. - Bird Conserv. Int. 23: 184-198.

Madroño, A., González, C. and Atienza, J. C. (Eds.) 2004. Libro Rojo de las Aves de España. Dirección General para la Biodiversidad-SEO/BirdLife, Madrid.

Márquez-Ferrando, R., Figuerola, J., Hooijmeijer, J. C., and Piersma, T. 2014. Recently created manmade habitats in Doñana provide alternative wintering space for the threatened Continental European black-tailed godwit population. - Biol. Conserv. 171: 127-135.

Masero, J. A. 2003. Assessing alternative anthropogenic habitats for conserving waterbirds: salinas as buffers against the impact of natural habitat loss for shorebirds. - Biodiv. Conserv. 12: 1157-1173.

Meli, P., Rey-Benayas, J. M., Balvanera, P. and Martínez Ramos, M. 2014. Restoration enhances wetland biodiversity and ecosystem service supply, but results are context-dependent: A meta-analysis. PLoS ONE 94: e93507.

Mitsch, W.J. and Gosselink, J.G. 2007. Wetlands. Hoboken, New Jersey, USA.

Moreno-Mateos, D., Power, M.E., Comin, F.A. and Yockteng, R. 2012. Structural and Functional Loss in Restored Wetland Ecosystems. - Plos Biol. 101: e1001247

Paradis, E., Claude, J. and Strimmer, K. 2004. APE: analyses of phylogenetics and evolution in R language. - Bioinformatics 20: 289-290.

Perennou, C., Beltrame, C., Guelmami, A., Tomas-Vives, P. and Caessteker, P. 2012. Existing areas and past changes of wetland extend in the Mediterranean region: an overview. - Ecología Mediterránea 38: 53-66.

Ramo, C., Aguilera, E., Figuerola, J., Máñez, M. and Green, A.J. 2013. Long-term population trends of colonial wading birds breeding in Doñana (SW Spain) in relation to environmental and anthropogenic factors. - Ardeola 60: 305-326.

R Development Core Team, 2009. R: A Language and Environment for Statistical Computing. R Foundation for Statistical Computing, Vienna.

Rendon, M.A., Green, A.J., Aquilera, E. and Almaraz, P. 2008. Status, distribution and long-term changes in the waterbird community wintering in Doñana, south-west Spain. - Biol. Conserv. 141: 1371-1388.

'This article is protected by copyright. All rights reserved.' 
Rey Benayas, J.M., Newton, A.C., Diaz, A. and Bullock, J.M. 2009. Enhancement of biodiversity and ecosystem services by ecological restoration: a meta-analysis. - Science 325: 1121-1124.

Santoro, S., Mañez, M., Green, A.J. and Figuerola, J. 2010. Formation and growth of a heronry in a managed wetland in Doñana, southwest Spain. - Bird Study 57: 515-524.

Sebastián-González, E., Sánchez-Zapata, J. and Botella, F. 2010. Agricultural ponds as alternative habitat for waterbirds: spatial and temporal patterns of abundance and management strategies. - Eur. J. Wildl. Res. 56: 11-20.

Sebastián-González, E., Sánchez-Zapata, J.A., Botella, F., Figuerola, J., Hiraldo, F., Wintle, B. 2011. Cost-efficiency evaluation of management strategies: waterbirds in a wetland network. - Biol. Conserv. 144: 2354-2361.

Sebastián-González, E. and Green, A.J. 2014. Habitat use by waterbirds in relation to pond size, water depth and isolation: lessons from a restoration in Southern Spain. - Res. Ecol. 22: 311-318.

Sripanomyom, S., Round, P.D., Savini, T., Trisurat, Y. and Gale, G.A. 2011. Traditional salt-pans hold major concentrations of overwintering shorebirds in southeast Asia. - Biol. Conserv. 144: 526-537.

Srivastava, D.S., Cadotte, M.W., MacDonald, A.A.M., Marushia, R.G. and Mirotchnick, N. 2012. Phylogenetic diversity and the functioning of ecosystems. - Ecol. Lett. 15: 637-648.

Tilman, D., Reich, P.B., and Knops, J.M.H. 2006. Biodiversity and ecosystem stability in a decade-long grassland experiment. - Nature 441: 629-632

Trinidade-Filho, J., Sobral, F.L., Cianciaruso, M.V. and Loyola, R.D. 2012. Using indicator groups to represent bird phylogenetic and functional diversity. - Biol. Conserv. 146: 155-162.

Vane-Wright, R. I., Humphries, C. J. and Williams, P. H. 1991. What to protect - systematics and the agony of choice. - Biol. Conserv. 55: 235-54.

Walton, M.E.M., Vilas, C., Cañavate, J.P., Gonzalez-Ortegon, E., Prieto, A., van Bergeijk, S.A., Green, A.J., Librero, M., Mazuelos, N. and Le Vay, L. 2015. A model for the future: Ecosystem services provided by the aquaculture activities of Veta la Palma, Southern Spain. Aquaculture, in press. DOI:10.1016/j.aquaculture.2015.06.017

Webb, C., Ackerly, D., McPeek, M. and Donoghue, M. 2002. Phylogenies and community ecology. Annu. Rev. Ecol. System. 33: 475-505.

Williams, P.B. and Faber, P.M. 2001. Salt marsh restoration experience in the San Francisco Bay Estuary. - J. Coast. Res., Special Issue 27: 203-211.

'This article is protected by copyright. All rights reserved.' 
Wilmers, C.C., Sinha, S. and Brede, M. 2002. Examining the effects of species richness on community stability: an assembly model approach. - Oikos 99: 363-367

Winter, M., Devictor, V. and Schweiger, O. 2013. Phylogenetic diversity and nature conservation: where are we? - Trends Ecol. Evol. 28: 199-204.

Supplementary material (Appendix EXXXXX at<www.oikosoffice.lu.se/appendix>). Appendix 1. 


\section{TABLE LEGENDS}

Table 1. Mean ( \pm standard error) values for the diversity indices and the percentage of threatened species for each wetland type, as well as the bird abundance and flooded surface area according to LANDSAT images. Abundance values are the average per survey. Other values are calculated per season (i.e. combining the three surveys in summer or winter for a given year).

\begin{tabular}{lccc} 
Diversity & Natural & Restored & Artificial \\
\hline Abundance & $3496.5 \pm 813.2$ & $4382.2 \pm 724.3$ & $2654.2 \pm 507.0$ \\
Richness & $19.16 \pm 0.86$ & $23.17 \pm 1.13$ & $16.65 \pm 0.67$ \\
Simpson & $0.75 \pm 0.016$ & $0.73 \pm 0.02$ & $0.65 \pm 0.02$ \\
Simpson biomass & $0.63 \pm 0.02$ & $0.61 \pm 0.02$ & $0.52 \pm 0.02$ \\
MPD & $154.23 \pm 0.76$ & $153.86 \pm 1.34$ & $148.28 \pm 2.43$ \\
MPWD & $114.11 \pm 3.20$ & $109.14 \pm 4.02$ & $98.10 \pm 2.48$ \\
Threatened IUCN & $3.39 \pm 0.42$ & $3.83 \pm 0.50$ & $2.25 \pm 0.25$ \\
Threatened Spain RDB & $35.80 \pm 8.94$ & $31.52 \pm 9.71$ & $30.30 \pm 12.76$ \\
Threatened Annex1 & $23.26 \pm 12.40$ & $23.95 \pm 10.75$ & $23.02 \pm 12.48$ \\
Threatened Europe & $13.62 \pm 5.53$ & $13.63 \pm 6.92$ & $9.72 \pm 7.57$ \\
Mean inundated area (ha) & $421.81 \pm 8.99$ & $2184.75 \pm 55.31$ & $595.22 \pm 3.66$
\end{tabular}

MPD: Mean Pairwise Distance. MPWD: Mean Pairwise Weighted Distance. Threatened species lists: IUCN (IUCN 2014), Spain RDB (Madroño et al. 2004), Annex 1 (Directive 2009/147/EC) and Europe (BirdLife International 2015). 
Table 2. Generalized linear mixed models of different diversity measures in relation to the wetland type (artificial, restored or natural). All models include abundance and the season (breeding vs. wintering) as covariates and year as random variable. We present the coefficients of the models for the covariates and the explanatory variable. We present the value of the $\Delta \mathrm{AIC}$ for the null models, relative to the models that included wetland type.

\begin{tabular}{lcccccc} 
Diversity & Intercept & Abundance & Restored & Artificial & Summer & $\Delta$ AIC \\
\hline Richness & 28.22 & 0.000062 & 0.18 & -0.12 & 0.0099 & 90.3 \\
Simpson & 0.73 & -0.0000023 & -0.021 & -0.102 & 0.00505 & 14.6 \\
Simpson biomass & 1.61 & 0.0000012 & -0.026 & -0.14 & -0.013 & 18.2 \\
MPD & 154.3 & 0.000055 & -0.501 & -5.78 & -1.33 & 1.4 \\
MPWD & 112.3 & -0.00023 & -4.38 & -16.55 & 8.19 & 12.7 \\
Threatened IUCN & 0.032 & 0.00000047 & 0.0032 & -0.011 & -0.0047 & 6.3 \\
Threatened Spain RDB & 61.41 & 0.00038 & -15.09 & -14.44 & 7.93 & 7.2 \\
Threatened Annex1 & 40.04 & -0.000079 & 4.25 & -1.71 & 36.61 & 2.0 \\
Threatened Europe & 47.86 & 0.000039 & -3.08 & -15.65 & -4.09 & 19.0 \\
\hline
\end{tabular}

MPD: Mean Pairwise Distance. MPWD: Mean Pairwise Weighted Distance. Threatened species lists: IUCN (IUCN 2014), Spain RDB (Madroño et al. 2004), Annex 1 (Directive 2009/147/EC) and Europe (BirdLife International 2015). Coefficients for natural wetlands and winter season are not included because they would be redundant (i.e. they are aliased), but they are effectively zero. 
Table 3. Turkey HSD post-hoc ANOVA comparing the predicted diversity measures and proportion of threatened species in different individual wetlands among wetland types (artificial, restored or natural). All the models include abundance and season (breeding vs. wintering) as covariates and year as random variable. We present p-values of post-hoc tests and the F and p-value of the ANOVA.

\begin{tabular}{|c|c|c|c|c|c|}
\hline \multirow[t]{2}{*}{ Diversity } & Natural- & Natural- & Restored- & \multirow[t]{2}{*}{$F$} & \multirow[t]{2}{*}{ P-value } \\
\hline & Restored & Artificial & Artificial & & \\
\hline Richness & 0.001 & 0.020 & $<0.001$ & 25.96 & $<0.001$ \\
\hline Simpson & 0.432 & $<0.001$ & $<0.001$ & 30.6 & $<0.001$ \\
\hline Simpson biomass & 0.519 & $<0.001$ & $<0.001$ & 44.28 & $<0.001$ \\
\hline MPD & 0.961 & $<0.001$ & $<0.001$ & 19.07 & $<0.001$ \\
\hline MPWD & 0.177 & $<0.001$ & $<0.001$ & 27.26 & $<0.001$ \\
\hline Threatened IUCN & 0.388 & $<0.001$ & $<0.001$ & 35.42 & $<0.001$ \\
\hline Threatened Spain RDB & 1.000 & 0.002 & 0.001 & 13.32 & $<0.001$ \\
\hline Threatened Annex1 & 0.533 & 0.154 & 0.818 & 1.717 & 0.181 \\
\hline Threatened Europe & 0.998 & $<0.001$ & $<0.001$ & 35.38 & $<0.001$ \\
\hline
\end{tabular}

MPD: Mean Pairwise Distance. MPWD: Mean Pairwise Weighted Distance. Threatened species lists: IUCN (IUCN 2014), Spain RDB (Madroño et al. 2004), Annex 1 (Directive 2009/147/EC) and Europe (BirdLife International 2015). 


\section{Figure legends}

Figure 1. Study area. Location of Doñana Natural Space in Spain. The map shows the location of the studied restored, artificial and natural wetlands. Numbers correspond to the details of each wetland in Table A1. Large parts of the restored areas shown are terrestrial habitats or dry out during several months, reducing the differences in size among natural, restored and artificial wetlands (see Supplementary material, Appendix 1, Table A1 and Figure A2 for wetland surface area and extent of flooding in winter).

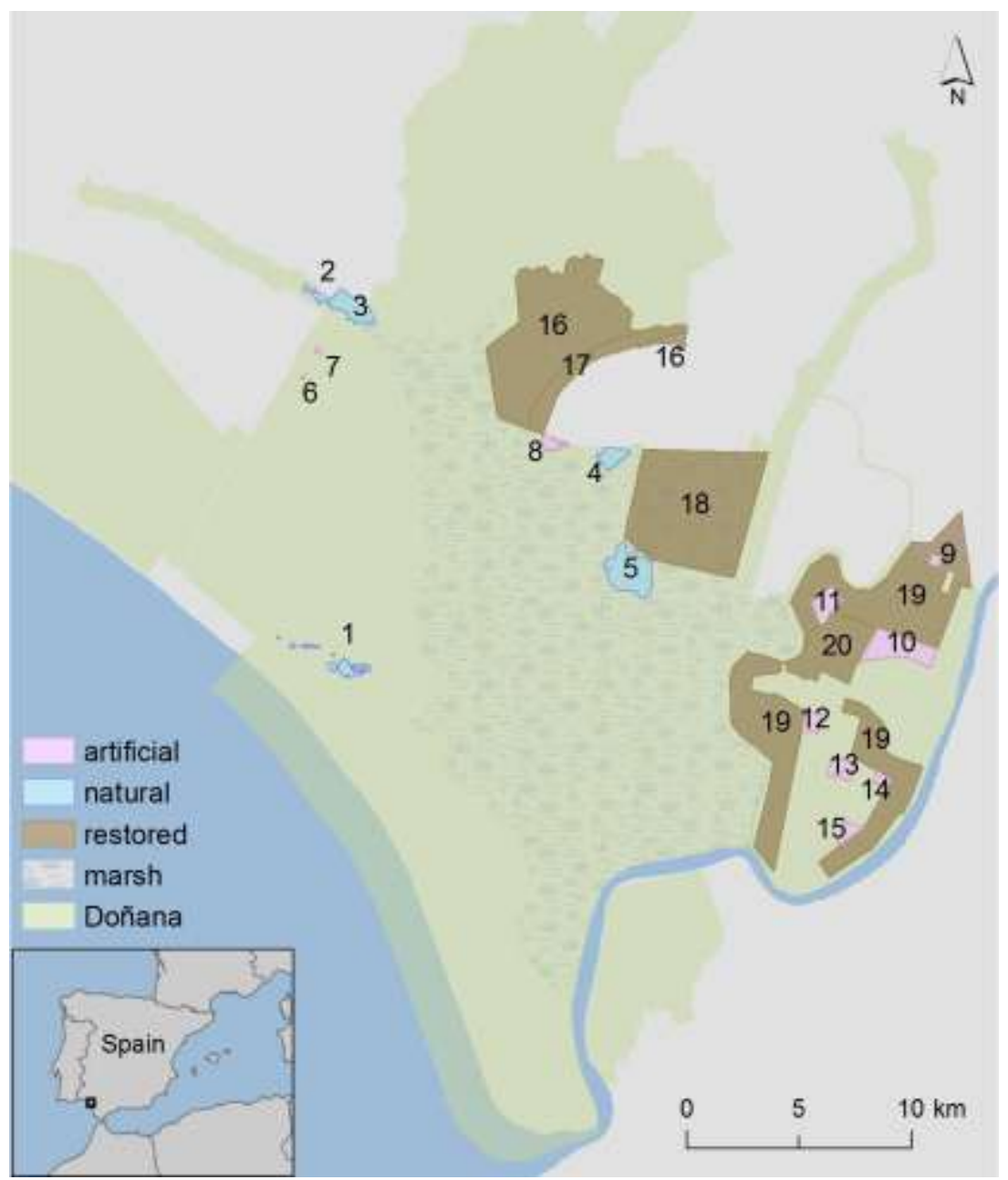


Figure 2. Boxplot of predicted diversity for natural, restored and artificial wetlands according to the models of Table 2. The models used for this figure include season and abundance as covariates, but do not include the year as a random variable. The graphs show the means, inter-quartile range and upper and lower whiskers for diversity predicted for the same season and abundance. Abbreviations as follows: Mean Pairwise Distance (MPD), Mean Pairwise Weighted Distance (MPWD).
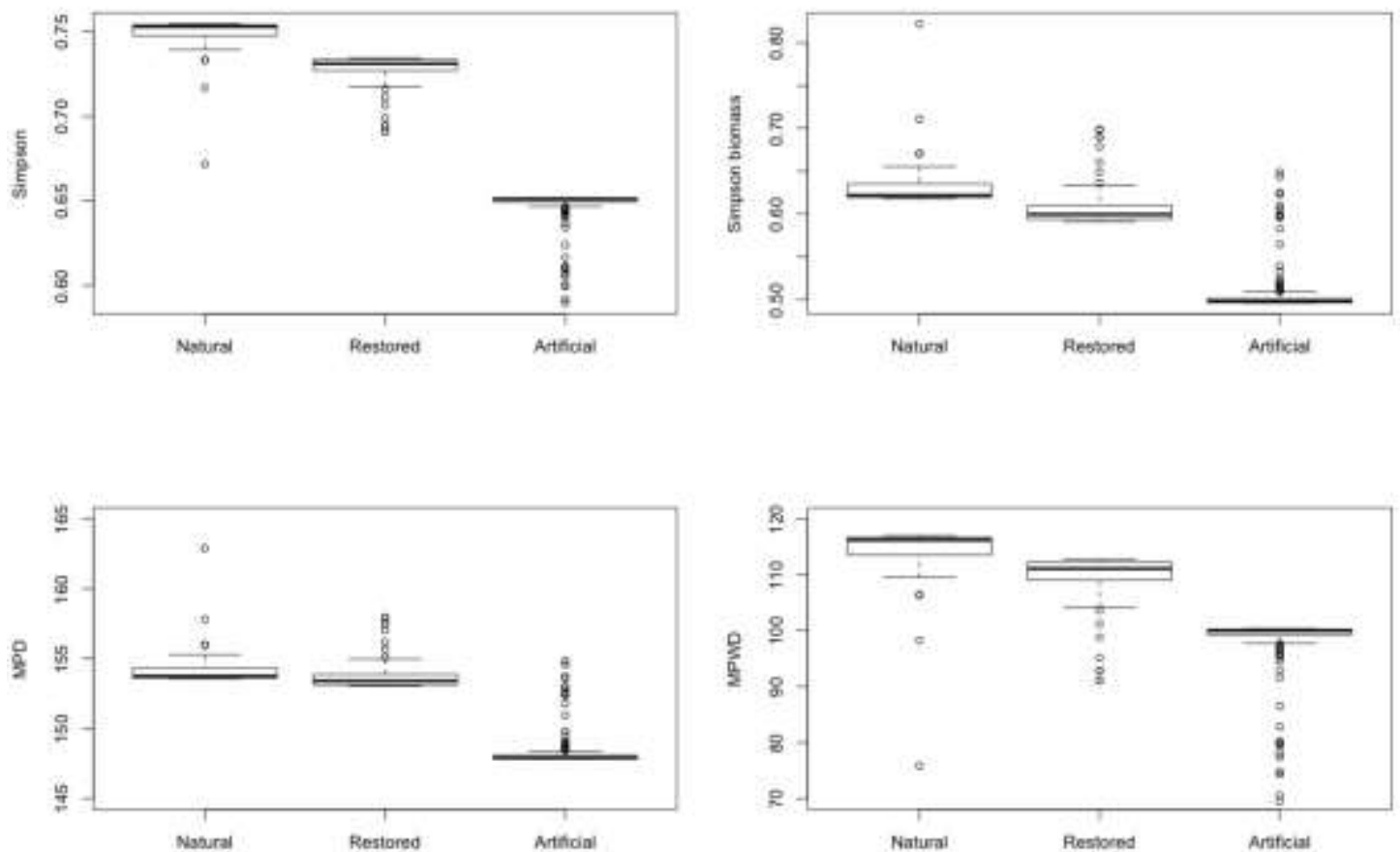
Figure 3. Boxplot of predicted proportion of threatened species for natural, restored and artificial wetlands according to the models of Table 2. The models used for this figure include season and abundance as covariates, but do not include the year as a random variable. The graphs show the means, inter-quartile range and upper and lower whiskers for the proportion of threatened species predicted for the same season and abundance values. Each graph corresponds to the proportion of threatened species under different criteria: IUCN global Red List, Red Data Book of the Birds of Spain, European Red List of Birds and Annex 1 of the European Birds Directive.
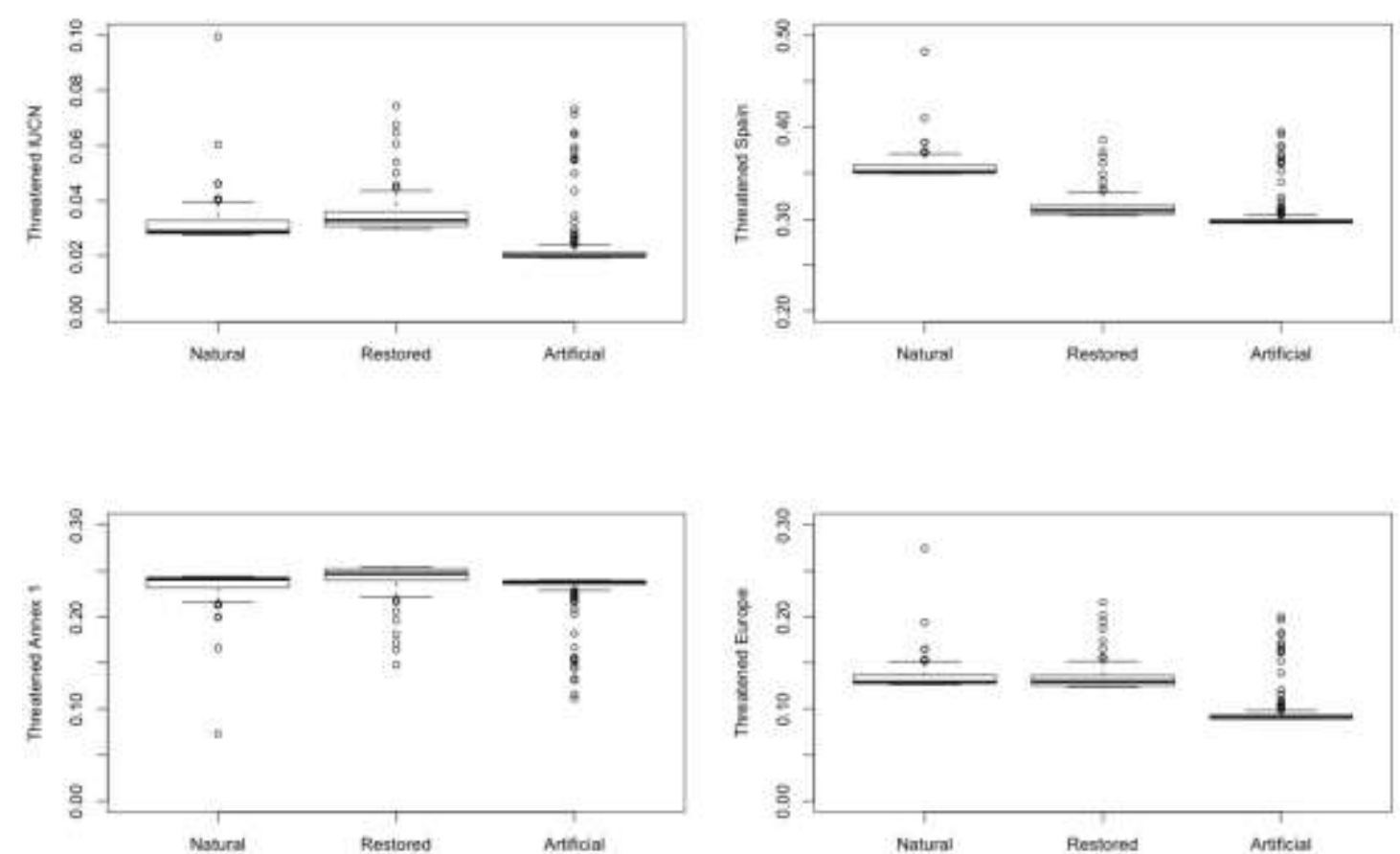